\title{
Effect of polymorphisms on TGFB1 on allergic asthma and helminth infection in an African admixed population
}

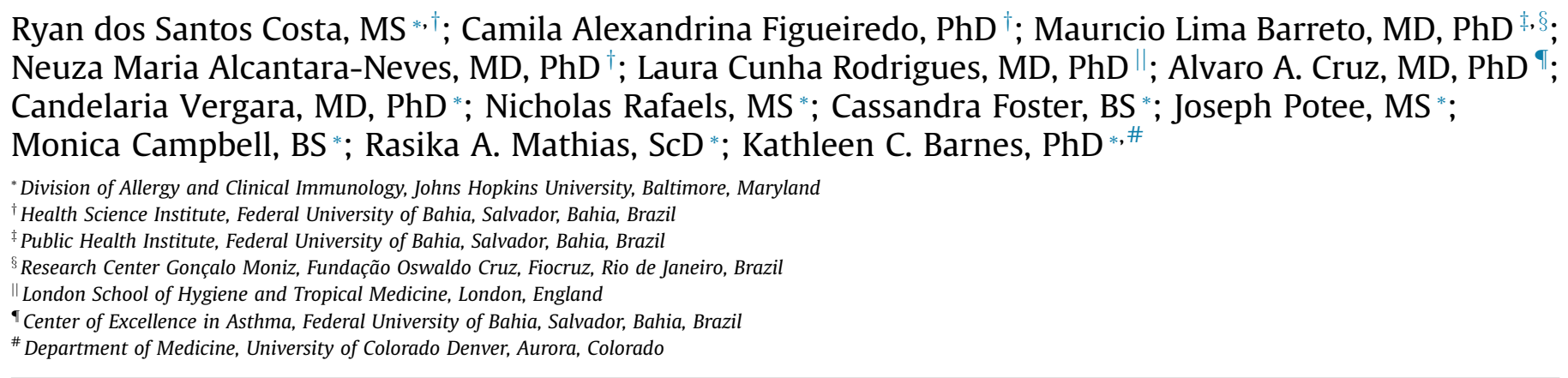

\section{A R T I C L E I N F O}

\section{Article history:}

Received for publication October 21, 2016.

Received in revised form January 18, 2017.

Accepted for publication January 31, 2017.
Reprints: Camila Alexandrina Figueiredo, PhD, Health Science Institute, Federal University of Bahia, Av. Reitor Miguel Calmon, s/n, Canela 40110-100, Salvador Bahia, Brazil; E-mail: cavfigueiredo@gmail.com. Disclosures: Authors have nothing to disclose.

Funding Sources: This study was supported by the Wellcome Trust, the HCPC Latin America Excellence Centre Programme (072405/Z/03/Z), and the Brazilian agency Conselho Nacional de Desenvolvimento Científico e Tecnológico-CNPq. Dr Barnes was supported in part by the Mary Beryl Patch Turnbull Scholar Program.

\section{A B S T R A C T}

Background: Allergic asthma is a complex disorder that results from a combination of genetic and environmental factors. Studies suggest that helminth infections can activate a regulatory network characterized by the production of regulatory cytokines, such as interleukin 10 and transforming growth factor $\beta 1$ (TGF- $\beta 1$ ) and subsequently protect against immune-mediated diseases, such as asthma. On the other hand, TGF- $\beta 1$ is increased in the lungs of individuals with asthma and may modulate airway inflammation. The role of TGF- $\beta 1$ single-nucleotide polymorphisms (SNPs) in allergic disease remains inconclusive.

Objective: To evaluate the effects of genetic variations in the TGF- $\beta 1$ on allergy and helminths infections in children.

Methods: We tested for association among 4 TGF- $\beta 1$ SNPs and allergic asthma, specific IgE, skin prick test result, and IL-10 production in 1,335 Brazilians. In addition, we analyzed the association with markers of helminth infection (parasite burden, anti-Ascaris IgE, and worm specific IgG4). The polymorphisms were genotyped using Taq Man probes.

Results: We found an association between rs1800470 (C allele) and atopic wheezing (odds ratio [OR], 0.60; 95\% confidence interval [CI], 0.37-0.95) and markers of allergy (OR, 0.41; 95\% CI, 0.22-0.79). In contrast, a positive association was observed between the haplotype ACCA and Trichuris trichiura infection (OR, 1.85; $P=.003)$ and Ascaris lumbricoides infection (OR, 2.01; $P<.001)$. This haplotype was also associated with increased IL-10 production $(\beta=50.7 ; P<.001)$.

Conclusion: Individuals with TGF- $\beta 1$ polymorphisms have an increased susceptibility to helminth infections and a lower risk of developing allergy. These studies suggest that immune modulation of allergic disease results not only from environmental factors but also from genetic susceptibility and IL-10 production.

(c) 2017 American College of Allergy, Asthma \& Immunology. Published by Elsevier Inc. All rights reserved. 
The temporal trend in the prevalence of allergic disease has been explained mainly by the hygiene hypothesis, originally proposed by Strachan, as a consequence of decreased exposure to pathogens (eg, helminths and bacteria) in the environment during childhood. ${ }^{7}$ The immune response against helminths is orchestrated by $\mathrm{T}_{\mathrm{H}} 2$ cytokine production, especially interleukin (IL) 4 and IL-5 that act on B cells to induce IgG and IgE class switching. ${ }^{8}$ To escape from host defense, the helminths develop robust immune regulatory mechanisms mediated by regulatory $\mathrm{T}$ (Treg) cells that act through the production of transforming growth factor $\beta 1$ (TGF- $\beta 1$ ) and IL-10. ${ }^{9-11}$

TGF- $\beta 1$ is a pleiotropic growth factor produced by various immune cells (epithelial cells, eosinophils, $\mathrm{T}_{\mathrm{H}} 2$ lymphocytes, macrophages, and fibroblasts) that plays a key role in regulation of the immune response during intracellular infections and inflammatory events by inhibiting the differentiation of immune cells $\left(T_{H} 1\right.$ lymphocytes, $\mathrm{T}_{\mathrm{H}} 2$ lymphocytes, and cytotoxic $\mathrm{T}$ cells and $\mathrm{B}$ cells) and cytokine production (interferon $\gamma$ and IL-2). ${ }^{12-14}$ Furthermore, TGF- $\beta 1$ is an important differentiation factor for regulatory T cells, exerting powerful and diverse immunosuppressive effects. ${ }^{15}$

In genetic association studies, polymorphisms in genes encoding TGF- $\beta 1$ have previously been associated with allergy and asthma phenotypes, including rs4803455, rs1800470, rs1800469, and rs2241712. ${ }^{16-20}$ The rs1800470 in the TGFB1 promoter and rs1800469 in codon 10 of exon 1 appear to influence TGF- $\beta 1$ blood levels and gene expression. ${ }^{21,22}$ Despite the prominent role that TGF- $\beta 1$ plays in helminthic infections, no association studies have been published examining the role of TGFB1 polymorphisms in risk of helminth infection and how it affects allergy. Given the important regulatory role of TGF- $\beta 1$ on inflammatory diseases and helminth infection, we sought to assess whether known polymorphisms in the TGFB1 gene are associated with asthma and allergic markers and whether they influence immunity to helminths.

\section{Methods}

\section{Study Population and Design}

The study population was selected from the city of Salvador in northeastern Brazil. The general study design has been extensively described elsewhere. ${ }^{9,10,23}$ Briefly, the study population included 1,335 unrelated children between 4 and 11 years old originally recruited in infancy by the program entitled Social Change, Asthma and Allergy in Latin America (SCAALA) for a prospective study that analyzed the effect of a citywide sanitation program on childhood morbidity. ${ }^{24}$

Data were collected from children born between 1994 and 2001 who lived in sentinel neighborhoods in the city. In 2000, stool samples were collected to characterize intestinal helminth infection. Children were resurveyed in 2005 to determine asthma status and to obtain stool and blood samples. Written informed consent was obtained from parents or the legal guardian of participants as approved by the Brazilian National Ethical Committee.

\section{Asthma Definition}

As previously described, ${ }^{25}$ children were classified as having current wheeze by using a Portuguese-adapted phase 2 International Study of Asthma and Allergies in Childhood questionnaire (wheezing in the last 12 months) ${ }^{26}$ and were considered to have asthma if there was a history of wheezing in the previous 12 months and at least 1 of the following: (1) asthma diagnosis, (2) wheezing with exercise in the last 12 months, (3) 4 or more episodes of wheezing in the last 12 months, and (4) waking up at night because of wheezing in the last 12 months.

\section{Specific Serum IgE Levels}

Determination of specific IgE (sIgE) levels were performed for Dermatophagoides pteronyssinus, Blomia tropicalis, Blattella germanica, and Periplaneta americana using the ImmunoCAP assay (Phadia Diagnostics AB, Uppsala Sweden). Values equal or greater than $0.70 \mathrm{kU} / \mathrm{L}$ were considered a positive result. Allergy status was defined according to having a positive result for at least $1 \operatorname{sigE}$ to aeroallergens.

\section{Skin Prick Tests}

Skin prick tests (SPTs) were performed on the right forearm of participants using standardized extracts (ALK-Abelló, São Paulo, Brazil) of $D$ pteronyssinus, $B$ tropicalis, $B$ germanica, $P$ americana, cat and dog epithelia, and a fungi mix (Aspergillus amstelodami, Aspergillus fumigatus, Aspergillus niger, Aspergillus terrus, Penicillium brevicompactum, Penicillium expansum, Penicillium notatum, Penicillium roqueforti, Cladosporium fulvum, and Cladosporium herbarum). Saline and a $10-\mathrm{mg} / \mathrm{mL}$ histamine solution were used as negative and positive controls, respectively. The reaction was read after 15 minutes. A reaction was considered positive if the wheal size was at least $3 \mathrm{~mm}$ greater than that elicited by the negative control.

\section{Parasitologic Analysis}

Stool samples were collected twice and analyzed for Ascaris lumbricoides and Trichuris trichiura infection at each of the 2 sampling times, 2 weeks apart. Stool samples were analyzed by using the Hoffman technique ${ }^{9}$ to determine the presence of helminths and the Kato-Katz technique ${ }^{27}$ to determine parasitic load. All children with positive results were appropriately treated. ${ }^{23}$ Occurrence of infections were defined as follows: (1) current infections, defined as infections with A lumbricoides, or $T$ trichiura detected in childhood (ie, survey conducted in 2005), and (2) coinfection, defined as children infected with A lumbricoides and T trichiura in 2005.

\section{Total Serum IgE Levels and Markers of Infection}

Total serum IgE (tIgE) levels were measured as previously described. ${ }^{9}$ Briefly, plate wells were coated with $4 \mathrm{mg} / \mathrm{mL}$ of an anti-human IgE antibody (BD PharMingen, San Diego, California) overnight at $4^{\circ} \mathrm{C}$, followed to blocking overnight at $4^{\circ} \mathrm{C}$. Samples were diluted 1:10 in diluent solution and incubated overnight at $4^{\circ} \mathrm{C}$. Plates were incubated with biotinylated anti-human IgE (SigmaAldrich, St Louis, Missouri), followed by streptavidin-peroxidase (BD PharMingen) and hydrogen peroxide-orthophenylenediamine substrate (Merck, White House Station, New Jersey) and read with a 480-nm filter.

Determination of worm sIgE was performed for A lumbricoides using the ImmunoCAP assay (Phadia Diagnostics AB). Anti-A lumbricoides sIgE levels equal or greater than $0.35 \mathrm{kU} / \mathrm{L}$ were considered positive results. Anti-A lumbricoides IgG4 was detected by indirect enzyme-linked immunosorbent assay (ELISA) as previously described. ${ }^{9}$ Briefly, plate wells were sensitized with $20 \mathrm{mg} / \mathrm{mL}$ of $A$ lumbricoides antigen. Serum samples were diluted 1:50 in diluent solution. Plates were incubated with biotinylated anti-human IgG4 (Sigma-Aldrich), followed by streptavidin-peroxidase (BD PharMingen) and hydrogen peroxide-orthophenylenediamine substrate (Merck) and read with a 480-nm filter. The assay cutoff for IgG4 for A lumbricoides was determined as the mean (SD) of negative controls (serum samples from children with 3 negative stool samples collected serially). Antibody levels of anti-A lumbricoides IgG4 more than the cutoff were defined as positive results.

Anti-Toxocara canis IgG antibodies were detected in serum samples by indirect ELISA assay using excretory-secretory $T$ canis 
Table 1

Description of SNPs Analyzed in This Study

\begin{tabular}{lllllll}
\hline SNP & Base pairs & Allele & MAF & HWE & Function GVS & Regulome DB score \\
\hline rs4803455 & 41855515 & A/C & 0.49 & 0.53 & Intron & 7 \\
rs1800470 & 41858921 & C/T & 0.47 & 0.57 & Missense & 4 \\
rs1800469 & 41860296 & T/C & 0.33 & 0.79 & Near gene 5 & $2 \mathrm{~b}$ \\
rs2241712 & 41869756 & G/A & 0.28 & 1 & Intron & 2b \\
\hline
\end{tabular}

Abbreviations: DB, database; GVS, genome variation server; HWE, Hardy-Weinberg equilibrium; MAF, minor allele frequency; SNP, single-nucleotide polymorphism.

larval antigens as previously described. ${ }^{28}$ The cutoff obtained (0.23) was calculated by the odds ratio (OR) from the mean of the 14 negative controls (children without history of contact with dogs and/or cats) plus 3 SDs of this mean. Five previously assayed serum samples were used as positive controls.

\section{Cell Culture for IL-10 Production}

Venous blood was collected into heparinized tubes and cultured at a dilution of 1:4 in RPMI (Gibco, Auckland, New Zealand) containing $10 \mathrm{mmol} / \mathrm{L}$ glutamine (Sigma-Aldrich) and $100 \mathrm{mg} / \mathrm{mL}$ of gentamicin (Sigma-Aldrich). The cell cultures were started within 6 hours after the blood collection and were maintained in a humidified environment of $5 \%$ carbon dioxide at $37^{\circ} \mathrm{C}$ for 24 hours for IL-10 detection in the absence or presence of pokeweed mitogen (Sigma-Aldrich) $(2.5 \mu \mathrm{g} / \mathrm{mL})$.

\section{IL-10 Measurement Using ELISA}

The IL-10 concentrations were measured in whole-blood culture supernatant by sandwich ELISA, according to the manufacturer's instructions (BD PharMingen). Cytokine concentrations were determined by means of interpolation of standard curves. The detection limits (low/high) were 31.25/500 pg/mL.

\section{Genotyping}

Four TGFB1 SNPs with prior associations with related phenotypes (rs4803455, rs1800470, rs1800469, rs2241712) were selected for genotyping. ${ }^{18,19}$ DNA was extracted from peripheral blood samples by using commercial standard protocols (Gentra Puregene Blood Kit; Qiagen, Hilden, Germany). SNPs were typed by using the TaqMan probe-based, 59-nuclease assay minor groove binder chemistry $^{29}$ on the 7900HT Sequence Detection System (Applied Biosystems, Foster City, California). TaqMan-validated assays and master mix were manufactured by Applied Biosystems.
Polymerase chain reaction was conducted in a $5-\mathrm{mL}$ volume by using a universal master mix and 4 predesigned and validated TaqMan assays for the SNPs (list of SNPs is given in Table 1). The thermal cycling conditions were as follows: $95^{\circ} \mathrm{C}$ for 10 minutes followed by 40 cycles of $95^{\circ} \mathrm{C}$ for 15 seconds and $60^{\circ} \mathrm{C}$ for 1 minute and an extension step of $60^{\circ} \mathrm{C}$ for 5 minutes. Nontemplate-negative and genotyping-positive controls were included in each genotyping plate. Automatic calling was performed with a quality value of greater than $99 \%$.

Ten percent of the samples were genotyped in duplicate with 100\% reproducibility. All 4 SNPs were in Hardy-Weinberg equilibrium. Allele frequencies of the SNPs and SNP localization in the TGF $\beta 1$ gene (chromosome 19q13.1, position 41330531 to 41353933) are summarized in Table 1. Markers rs1800469 and rs2241712 are in strong linkage disequilibrium (eFig 1) by Haploview. $^{30}$

\section{Statistical Analysis}

Genotype and haplotype analyses were conducted for genetic associations using logistic regression to estimate ORs and 95\% confidence intervals (CIs) for the genetic risk factor (including sex, age, and helminth infection as covariates). In the population of the current study, a negative association was previously described between $T$ trichiura (mainly) and A lumbricoides infections and a SPT responses. ${ }^{31}$ In addition, there is crossreactivity between the helminth-induced $\operatorname{IgE}$ and anti-IgE against aeroallergens. Thus, we have adjusted such models for helminth infections. ${ }^{31}$

In addition, the first 2 principal components delineated through Eigenstrat on 269 ancestry informative markers were included in the model to address the potential effects of population stratification. Genotype analyses were performed using the additive, dominant, and recessive models.

For continuous data (tIgE, anti-A lumbricoides IgG4, and anti-A lumbricoides IgE), analyses were conducted by using linear regression adjusted by sex, age, helminth infection, and principal components 1 and 2 . All genetic analyses were performed using PLINK 1.07,32 and pairwise linkage disequilibrium was created with Haploview. ${ }^{30}$ The differences were considered significant at $P<.05$. In addition, the permutation procedures were calculated to provide a computationally intensive approach to generating significance levels. This strategy has been used to control the false discovery rate solving the problem of multiple comparisons. $^{33}$

Table 2

Characteristics of the Social Changes Asthma and Allergy in a Latin American Population According to Asthma Status and Study Variables

\begin{tabular}{|c|c|c|c|c|}
\hline & $\begin{array}{l}\text { Patients without } \\
\text { asthma }(\mathrm{n}=962)\end{array}$ & $\begin{array}{l}\text { Patients with asthma and } \\
\text { without allergy }(n=212)\end{array}$ & $\begin{array}{l}\text { Patients with allergy } \\
\text { and asthma }(\mathrm{n}=178)\end{array}$ & $P$ value \\
\hline Age, $y$ & & & & $<.001$ \\
\hline$\leq 5$ & $290(30.40)$ & $108(50.94)$ & $75(42.13)$ & \\
\hline $6-7$ & 351 (36.79) & $67(31.60)$ & $59(33.15)$ & \\
\hline$\geq 8$ & $313(32.81)$ & $37(17.45)$ & $44(24.72)$ & \\
\hline Sex & & & & .048 \\
\hline Male & $517(53.74)$ & $101(47.64)$ & $107(60.11)$ & \\
\hline Female & $445(46.26)$ & $111(52.36)$ & $71(39.89)$ & \\
\hline Skin prink test response $\geq 1$ allergen $(>3 \mathrm{~mm}$ ) & $268(27.86)$ & $21(9.91)$ & $117(65.73)$ & $<.001$ \\
\hline Skin prink test to Blomia tropicalis ( $>3 \mathrm{~mm}$ ) & $192(19.96)$ & $10(4.72)$ & $90(50.56)$ & $<.001$ \\
\hline Specific IgE for $\geq 1$ allergen $(>0.70 \mathrm{kU} / \mathrm{L})$ & $331(34.41)$ & 0 & $178(100.00)$ & $<.001$ \\
\hline Total IgE $(\mathrm{kU} / \mathrm{L})$, mean $(\mathrm{SD})$ & $0.80(5.46)$ & $0.28(0.60)$ & $1.71(4.59)$ & .02 \\
\hline Toxocara canis current infection & $443(46.05)$ & $101(47.64)$ & $88(49.44)$ & .89 \\
\hline Trichuris trichiura current infection & $124(12.89)$ & $39(18.40)$ & $21(11.80)$ & .19 \\
\hline IgG4 anti-Ascaris & $145(15.07)$ & $36(16.98)$ & $38(21.35)$ & .23 \\
\hline IgE anti-Ascaris & $462(48.02)$ & $80(37.74)$ & $138(77.53)$ & $<.001$ \\
\hline Coinfection (Ascaris lumbricoides and T trichiura) & $210(21.83)$ & $62(29.25)$ & $39(21.91)$ & .17 \\
\hline
\end{tabular}

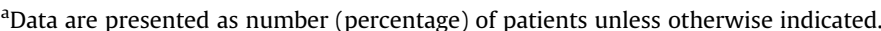


Table 3

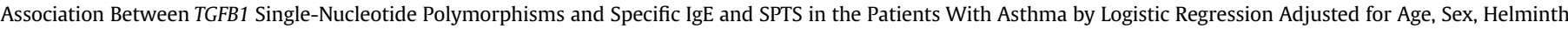
Infections, and Major Components 1 and 2

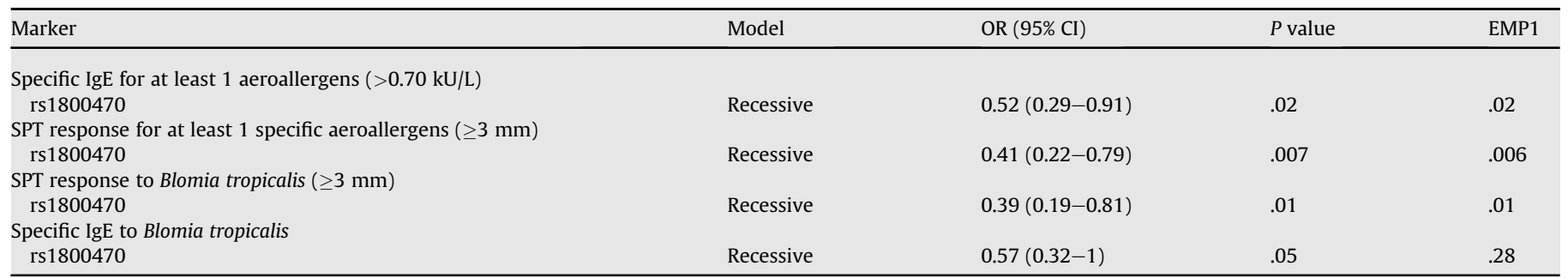

Abbreviations: $\mathrm{CI}$, confidence interval; EMP1, empirical $P$ value considering adaptive permutations; OR, odds ratio; SPT, skin prick test.

\section{Results}

\section{Description of the Study Population}

Table 2 summarizes the clinical characteristics of the study population. We observed greater proportions of children with allergic and nonallergic asthma in the younger group ( $<5$ years old); however, no difference according to sex was observed. Markers of allergy, specifically SPT reactivity $(65.73 \% ; P<.001)$ and total IgE levels $(1.71 \mathrm{kU} / \mathrm{mL} ; P<.05)$, were significantly higher in the allergic asthmatic group compared with the nonasthmatic group. IgE anti-A lumbricoides $(77.53 \% ; P<.001)$ was great in those with allergic asthma.

\section{Association of TGFB1 SNPS With Allergic Asthma and Markers of Allergy}

The TGFB1 marker rs1800470 was negatively associated (OR, $0.60 ; 95 \% \mathrm{CI}, 0.37-0.95 ; P=.03$; empirical $P$ value considering adaptive permutations $=.02$ ) with allergic asthma in the recessive model. This marker was similarly negatively associated with sIgE to at least one allergen tested (OR, 0.52; $P<.05)$, with skin test to at least 1 allergen (OR, $0.41 ; P<.01$ ) and skin test reactivity to $B$ tropicalis (OR, 0.39; $P<.05)$ under the recessive model (Table 3 ).

\section{Association of TGFB1 SNPs and tIgE}

No associations were observed between any of the TGFB1 markers and tIgE levels under any of the models tested (data not shown). However, the haplotypes TT $(\beta,-0.156 ; P<.05)$, CTT $(\beta,-0.162 ; P<.05)$, TTG $(\beta,-0.211 ; P<.01)$, and CTTG $(\beta,-0.197 ; P$ $<.01$ ) were negatively associated with tIgE levels (Table 4 ).

\section{Association of TGFB1 SNPs and Helminth Infections}

No association was found considering analysis between single genotype with helminth infections and markers of infection (data not shown). However, evaluating the association of possible haplotypes with helminth infections, significant associations were observed (Table 5). Specially, haplotypes AC, ACC, and ACCA had a positive association with T canis infection (ORs, 1.73, 2.09, and 2.07, respectively; $P<.001$ ), $T$ trichiura current infection (ORs, $1.80,1.80$, and 1.85 , respectively; $P<.01$ ), and coinfection with $T$ trichiuras and

\section{Table 4}

Association Between the TGFB1 Single-Nucleotide Polymorphisms and Total IgE in Total Case-Control Participants by Linear Regression Adjusted for Age, Sex, Helminth Infections, and Principal Components 1 and 2

\begin{tabular}{|c|c|c|c|c|c|c|c|}
\hline rs4803455 & rs1800470 & rs1800469 & rs2241712 & Frequency & $\beta$ & $P$ value & EMP1 \\
\hline & $\mathrm{T}$ & $\mathrm{T}$ & & 0.0343 & -0.156 & .01 & .01 \\
\hline C & $\mathrm{T}$ & $\mathrm{T}$ & & 0.0281 & -0.162 & .02 & .02 \\
\hline & $\mathrm{T}$ & $\mathrm{T}$ & G & 0.029 & -0.211 & .003 & .004 \\
\hline C & $\mathrm{T}$ & $\mathrm{T}$ & G & 0.0271 & -0.197 & .006 & .005 \\
\hline
\end{tabular}

Abbreviation: EMP1, empirical $P$ value considering adaptive permutations.
A lumbricoides (ORs, 1.61, 1.63, and 1.67, respectively; $P<.01$ ). By linear regression, $\mathrm{CC}(\beta, 1.67 ; P<.001), \operatorname{CCC}(\beta, 1.48 ; P<.05), \operatorname{CCA}(\beta$, $1.57 ; P<.001)$, and CCCA $(\beta, 1.4 ; P<.05)$ haplotypes were positively associated with IgG4 anti-A lumbricoides serum levels (eTable 1 ).

\section{Association of TGFB1 SNPs With Allergic Asthma in Helminth} Infected or Uninfected Individuals

Marker rs1800470 was negatively associated (OR, $0.31 ; P<.001)$ with allergic asthma (recessive model) among the individuals infected with $T$ canis (Table 6) but not among the uninfected individuals. There was no association with allergic asthma in the subgroup analysis for infected and noninfected individuals with $A$ lumbricoides or $T$ trichiura.

\section{Association of TGFB1 SNPs With IL-10 Levels}

No association was found when testing associations between any single marker and pokeweed stimulated IL-10 levels (data no shown). However, evaluating the possible haplotypes with basal IL-10 production from peripheral blood mononuclear cells without stimulus, we found a positive association with $\mathrm{AC}(\beta, 9.78 ; P<.05)$, $\operatorname{ACC}(\beta, 21.7 ; P<.05)$, and ACCA $(\beta, 12.6 ; P<.05)$ (Table 7$)$. These haplotypes were also associated with levels of IL-10 production under pokeweed stimulation: AC $(\beta, 46.8 ; P<.001)$, ACC $(\beta, 51.1$; $P<.001)$, and ACCA $(\beta, 50.7 ; P<.001)$ (eTable 2$)$.

\section{Discussion}

Allergy is a complex disease in which environmental factors interact with multiple genetic variants modifying it susceptibility and severity. To elucidate the effect of the immune regulatory network on allergic disease and parasitic diseases, we investigated the role of common genetic polymorphisms in TGFB1, an important immune regulatory cytokine. We found that TGFB1 polymorphisms are negatively associated with allergic asthma and associated phenotypes and positively associated with helminth infections in a population of children living in Salvador, an urban, tropical environment for which extracellular parasitic disease is endemic. This observation may contribute to the better understanding of the importance of genetic variability on the modulation of allergic processes by helminth infections.

Of the 4 TGFB1 SNPs evaluated in this study, the CC genotype of rs1800470 (T869C) had a negative association with allergic asthma, serum sIgE to common allergens, and skin test reactivity to allergens, including house dust mite $B$ tropicalis. However, several previous studies have described no association for rs1800470 with asthma, ${ }^{34-36}$ and few studies found a positive association..$^{20,37}$ The discrepant results may be consequence of the linkage disequilibrium with other variants within or near TGFB1, the ethnical differences among the studied populations, and/or untested gene-by-gene or gene-by-environment interactions. 
Table 5

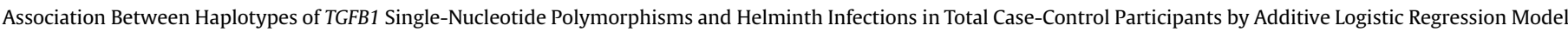
Adjusted for Age, Sex, and Principal Components 1 and 2

\begin{tabular}{|c|c|c|c|c|c|c|c|c|c|c|c|c|}
\hline \multirow[t]{2}{*}{ Trait } & \multicolumn{4}{|l|}{$\mathrm{AC}^{\mathrm{a}}$} & \multicolumn{4}{|l|}{$\mathrm{ACC}^{\mathrm{b}}$} & \multicolumn{4}{|c|}{$\mathrm{ACCA}^{\mathrm{C}}$} \\
\hline & $\mathrm{F}$ & OR & $P$ value & EMP1 & $\mathrm{F}$ & OR & $P$ value & EMP1 & $\mathrm{F}$ & OR & $P$ value & EMP1 \\
\hline Toxocara canis seroprevalence & 0.8 & 1.73 & $<.001$ & $<.001$ & 0.08 & 2.09 & $<.001$ & $<.001$ & 0.08 & 2.07 & $<.001$ & $<.001$ \\
\hline Tricuris trichiura current infection & 0.12 & 1.80 & .001 & .003 & 0.09 & 1.80 & .005 & .01 & 0.09 & 1.85 & .004 & .008 \\
\hline Anti-Ascaria lumbricoides IgE & 0.09 & 1.49 & .01 & .03 & 0.07 & 1.58 & .01 & .04 & 0.07 & 1.61 & .01 & .03 \\
\hline Anti-A lumbricoides IgG4 & 0.12 & 1.80 & $<.001$ & .001 & 0.09 & 1.92 & $<.001$ & .002 & 0.10 & 2.01 & $<.001$ & .001 \\
\hline Coinfection ( $A$ lumbricoides and $T$ trichiura) & 0.11 & 1.61 & .004 & .01 & 0.08 & 1.63 & .01 & .03 & 0.08 & 1.67 & .007 & .02 \\
\hline
\end{tabular}

Abbreviations: EMP1, empirical $P$ value considering adaptive permutations; OR, odds ratio.

${ }^{a}$ rs4803455 and rs1800470.

brs4803455, rs1800470, and rs1800469.

crs4803455, rs1800470, rs1800469, and rs2241712.

Further work on this polymorphism is required to better understand their association with asthma.

The marker rs 1800470 has also been reported to be associated with serum levels of the gene product, with the CC genotype associated with higher TGF- $\beta 1$ concentration than other genotypes. ${ }^{38,39}$ The association of TGF- $\beta 1$ levels with allergy has been explored in several experimental studies. Intratracheal delivery of TGF- $\beta 1$ suppressed allergen-induced inflammation. ${ }^{11}$ In contrast, blocking TGF- $\beta /$ Smad signaling in T cells enhances antigen-induced airway inflammation, airway reactivity, and increased $\mathrm{T}_{\mathrm{H}} 2$ cytokine production. ${ }^{40}$ Moreover, reduced expression of TGF- $\beta 1$ exacerbates pathologic findings in an experimental asthma model related with increased eosinophilic inflammation and increased levels of specific IgE in serum. ${ }^{41}$

IgE is an important mediator involved in the allergic process and the immune response against helminths. IgE production is induced by $\mathrm{T}_{\mathrm{H}} 2$ cytokines, whereas immune regulatory cytokines (eg, IL-10 and TGF- $\beta 1$ ) down-regulate IgE levels. ${ }^{42}$ We identified 4 haplotypes in the TGFB1 gene negatively associated with tIgE levels in this population that characterizes the immunomodulatory property of TGF- $\beta 1$. However, previous studies have found no association between TGFB1 SNPs and tIgE levels. ${ }^{43,44}$ Because of its immune modulatory properties, TGF- $\beta 1$ also leads to a failure in the immune response against helminths, resulting in increased susceptibility to infections. A study of children infected with helminths identified increased production of TGF- $\beta 1$ in unstimulated peripheral blood leukocytes, being positively associated with burden of infection and negatively associated with immune reactivity, determined by IL- 4 and interferon $\gamma$ production and cell proliferation in response to antigenic stimuli. ${ }^{45}$ In this study, we evaluated the association between the TGFB1 polymorphism and helminth infections. Although no association was found between TGFB1 genotypes and helminth infections, analysis of possible haplotypes as a mean of simultaneous SNPs occurring together, especially the haplotypes formed by the C allele of rs1800470 with the other SNPs, was positively associated with helminth infections, indicating that TGFB1 polymorphisms contribute to susceptibility to parasitic infections. This study was the first, to our knowledge, to describe the association of polymorphism in the TGFB1 gene and infection by
T canis, $T$ trichiura, and A lumbricoides. The results suggest that the genetic background may influence the susceptibility and resolution of the helminth infection. Therefore, the individual genetically predisposed when exposed to helminths will probably have a higher immunomodulatory response, characterized by high TGF and IL-10 production, an important mechanism of escape of the effector immune response against the helminths.

The association between helminth infection and TGF- $\beta 1$ production seems to also influence the development of allergic diseases through the modulation of the $\mathrm{T}_{\mathrm{H}} 2$ response. ${ }^{31,46,47}$ The interaction with the environment (eg, infections) can represent an important role on the manifestation of genetic susceptibility. In fact, we found that the CC genotype of rs1800470 is negatively associated with allergic asthma in individuals infected with Tcanis. However, this association was lost when only individuals infected with $T$ canis were analyzed. Thus, we found that $T$ canis infection contributes to the modulation of the immunologic response on allergies on genetically susceptible individuals. Thus, the intense immune regulatory role played by TGF- $\beta 1$ induced in infected individuals may explain the protection against the development of immune-mediated diseases. $7,45,48$

Our group previously found in the same population that children chronically infected with helminths produce higher levels of immune regulatory cytokine IL- $10 .^{9}$ In addition, in the SCAALA population, our group found that the association between allergies and IL-10 levels is determined not only by environmental factors but also as a result of polymorphisms in the IL10 gene that are positively associated with allergy and negatively associated with helminth infections. ${ }^{17}$ TGF- $\beta 1$ is the primary regulator of the immune response acting as an important factor by inducing the differentiation and development of Foxp3 + regulatory T cells and thus for the IL-10 production. ${ }^{49,50}$ For this reason, we investigated whether polymorphisms in TGFB1 can affect production of IL-10. We found that the TGFB1 haplotypes were positively associated with spontaneous IL-10 production and IL-10 production stimulated by pokeweed mitogen. Such haplotypes were the same as those associated with helminth infections. Thus, polymorphisms not only in the IL10 gene but also in TGFB1 are involved in
Table 6

Association Between TGFB1 Single-Nucleotide Polymorphisms and Allergic Asthma in Toxocara canis Infected and Uninfected Individuals by Logistic Regression Adjusted for Age, Sex, Helminth Infections and Principal Components 1 and 2

\begin{tabular}{|c|c|c|c|c|}
\hline Marker & Model & OR $(95 \% \mathrm{CI})$ & $P$ value & EMP1 \\
\hline \multicolumn{5}{|c|}{ Allergic asthma ( $T$ canis infected individuals) } \\
\hline rs1800470 & Recessive & $0.31(0.14-0.72)$ & .006 & .006 \\
\hline \multicolumn{5}{|c|}{ Allergic asthma ( $T$ canis uninfected individuals) } \\
\hline rs1800470 & Recessive & $0.84(0.44-1.59)$ & 60 & .75 \\
\hline
\end{tabular}

Abbreviations: $\mathrm{CI}$, confidence interval; EMP1, empirical $P$ value considering adaptive permutations; OR, odds ratio; SPT, skin prick test.

\section{Table 7}

Association Between TGFB1 Haplotypes and Spontaneous Interleukin 10 Production in Total Case-Control Participants by Linear Regression Adjusted for Age, Sex, Helminth Infections, and Principal Components 1 and 2

\begin{tabular}{llllllll}
\hline rs4803455 & rs1800470 & rs1800469 & rs2241712 & Frequency & $\beta$ & $P$ value & EMP1 \\
\hline $\mathrm{A}$ & $\mathrm{C}$ & & & 0.08 & 9.78 & .03 & .03 \\
$\mathrm{~A}$ & $\mathrm{C}$ & $\mathrm{C}$ & & 0.06 & 21.7 & .005 & .01 \\
$\mathrm{~A}$ & $\mathrm{C}$ & $\mathrm{C}$ & $\mathrm{A}$ & 0.06 & 12.6 & .02 & .02 \\
\hline
\end{tabular}

Abbreviation: EMP1, empirical $P$ value considering adaptive permutations. 
modulation of IL-10 levels, which may contribute to susceptibility to infection and potentially modulation of allergy.

Individuals with genetic polymorphisms in TGFB1 have a lower risk of developing allergy and increased susceptibility to helminth infections. In addition, we found that immune modulation of allergy is a complex response that results not only from the environmental factors but also from the genetic polymorphisms, especially IL-10 production. Future works are needed to further elucidate the potential role of TGF- $\beta 1$ on asthma and how it could be a strategy to control the disease.

\section{Acknowledgments}

We acknowledge the funding agencies that have supported this work and technical assistance from Pat Oldewurtel.

\section{Supplementary Data}

Supplementary data related to this article can be found at http:/ dx.doi.org/10.1016/j.anai.2017.01.028.

\section{References}

[1] Ober C, Yao TC. The genetics of asthma and allergic disease: a 21st century perspective. Immunol Rev. 2011;242:10-30.

[2] Murdoch JR, Lloyd CM. Chronic inflammation and asthma. Mutat Res. 2010; 690:24-39.

[3] To T, Stanojevic S, Moores G, et al. Global asthma prevalence in adults: findings from the cross-sectional world health survey. BMC Public Health. 2012;12:204.

[4] Pearce N, Aït-Khaled N, Beasley R, et al. Worldwide trends in the prevalence of asthma symptoms: phase III of the International Study of Asthma and Allergies in Childhood (ISAAC). Thorax. 2007;62:758-766.

[5] Cooper PJ, Rodrigues LC, Cruz AA, Barreto ML. Asthma in Latin America: a public heath challenge and research opportunity. Allergy. 2009;64:5-17.

[6] Jenerowicz D, Silny W, Dańczak-Pazdrowska A, Polańska A, OsmolaMańkowska A, Olek-Hrab K. Environmental factors and allergic diseases. Ann Agric Environ Med. 2012;19:475-481.

[7] Okada H, Kuhn C, Feillet H, Bach JF. The 'hygiene hypothesis' for autoimmune and allergic diseases: an update. Clin Exp Immunol. 2010;160:1-9.

[8] Anthony RM, Rutitzky LI, Urban JF, Stadecker MJ, Gause WC. Protective immune mechanisms in helminth infection. Nat Rev Immunol. 2007;7:975-987.

[9] Figueiredo CA, Barreto ML, Rodrigues LC, et al. Chronic intestinal helminth infections are associated with immune hyporesponsiveness and induction of a regulatory network. Infect Immun. 2010;78:3160-3167.

[10] Figueiredo CA, Alcantara-Neves NM, Amorim LD, et al. Evidence for a modulatory effect of IL-10 on both Th1 and Th2 cytokine production: the role of the environment. Clin Immunol. 2011;139:57-64.

[11] Joetham A, Takeda K, Takada K, et al. Naturally occurring lung CD4(+) CD25(+) T cell regulation of airway allergic responses depends on IL-10 induction of TGF-beta. J Immunol. 2007;178:1433-1442.

[12] Yang YC, Zhang N, Van Crombruggen K, Hu GH, Hong SL, Bachert C. Transforming growth factor-beta1 in inflammatory airway disease: a key for understanding inflammation and remodeling. Allergy. 2012;67:1193-1202.

[13] Yoshimura A, Wakabayashi Y, Mori T. Cellular and molecular basis for the regulation of inflammation by TGF-beta. J Biochem. 2010;147:781-792.

[14] Li MO, Wan YY, Sanjabi S, Robertson AK, Flavell RA. Transforming growth factor-beta regulation of immune responses. Annu Rev Immunol. 2006;24: 99-146.

[15] Li MO, Sanjabi S, Flavell RA. Transforming growth factor-beta controls development, homeostasis, and tolerance of $\mathrm{T}$ cells by regulatory $\mathrm{T}$ celldependent and -independent mechanisms. Immunity. 2006;25:455-471.

[16] Bottema RW, Kerkhof M, Reijmerink NE, et al. Gene-gene interaction in regulatory $\mathrm{T}$-cell function in atopy and asthma development in childhood. J Allergy Clin Immunol. 2010;126:338-346. 346.e1-10.

[17] Figueiredo CA, Barreto ML, Alcantara-Neves NM, et al. Coassociations between IL10 polymorphisms, IL-10 production, helminth infection, and asthma/wheeze in an urban tropical population in Brazil. J Allergy Clin Immunol. 2013;131:1683-1690.

[18] Wu H, Romieu I, Shi M, et al. Evaluation of candidate genes in a genome-wide association study of childhood asthma in Mexicans. J Allergy Clin Immunol. 2010;125:321-327.e13.

[19] Yang XX, Li FX, Wu YS, Wu D, Tan JY, Li M. Association of TGF-beta1, IL-4 and IL-13 gene polymerphisms with asthma in a Chinese population. Asian Pac J Allergy Immunol. 2011;29:273-277.

[20] Li H, Romieu I, Wu H, et al. Genetic polymorphisms in transforming growth factor beta-1 (TGFB1) and childhood asthma and atopy. Hum Genet. 2007; 121:529-538.

[21] Grainger DJ, Heathcote K, Chiano M, et al. Genetic control of the circulating concentration of transforming growth factor type beta1. Hum Mol Genet. 1999;8:93-97.
[22] Suthanthiran M, Li B, Song JO, et al. Transforming growth factor-beta 1 hyperexpression in African-American hypertensives: a novel mediator of hypertension and/or target organ damage. Proc Natl Acad Sci U S A. 2000;97:3479-3484.

[23] Barreto ML, Cunha SS, Alcântara-Neves N, et al. Risk factors and immunological pathways for asthma and other allergic diseases in children: background and methodology of a longitudinal study in a large urban center in Northeastern Brazil (Salvador-SCAALA study). BMC Pulm Med. 2006;6:15.

[24] Barreto ML, Genser B, Strina A, et al. Impact of a citywide sanitation program in Northeast Brazil on intestinal parasites infection in young children. Environ Health Perspect. 2010;118:1637-1642.

[25] Alcantara-Neves NM, Veiga RV, Dattoli VC, et al. The effect of single and multiple infections on atopy and wheezing in children. J Allergy Clin Immunol. 2012;129:359-367. 367.e1-3.

[26] Weiland SK, Björkstén B, Brunekreef B, et al. Phase II of the International Study of Asthma and Allergies in Childhood (ISAAC II): rationale and methods. Eur Respir J. 2004;24:406-412.

[27] Katz N, Chaves A, Pellegrino J. A simple device for quantitative stool thicksmear technique in Schistosomiasis mansoni. Rev Inst Med Trop Sao Paulo. 1972; $14: 397-400$.

[28] Mendonça LR, Figueiredo CA, Esquivel R, et al. Seroprevalence and risk factors for Toxocara infection in children from an urban large setting in Northeast Brazil. Acta Trop. 2013;128:90-95.

[29] Livak KJ. Allelic discrimination using fluorogenic probes and the 5' nuclease assay. Genet Anal. 1999;14:143-149.

[30] Barrett JC, Fry B, Maller J, Daly MJ. Haploview: analysis and visualization of LD and haplotype maps. Bioinformatics. 2005;21:263-265.

[31] Rodrigues LC, Newcombe PJ, Cunha SS, et al. Early infection with Trichuris trichiura and allergen skin test reactivity in later childhood. Clin Exp Allergy. 2008;38:1769-1777.

[32] Purcell S, Neale B, Todd-Brown K, et al. PLINK: a tool set for whole-genome association and population-based linkage analyses. Am J Hum Genet. 2007; 81:559-575.

[33] Lage-Castellanos A, Martinez-Montes E, Hernandez-Cabrera JA, Galan L. False discovery rate and permutation test: an evaluation in ERP data analysis. Stat Med. 2010;29:63-74.

[34] Heinzmann A, Bauer E, Ganter K, Kurz T, Deichmann KA. Polymorphisms of the TGF-beta1 gene are not associated with bronchial asthma in Caucasian children. Pediatr Allergy Immunol. 2005;16:310-314.

[35] Li H, Li Y, Zhang M, et al. Associations of genetic variants in ADAM33 and TGF$\beta 1$ genes with childhood asthma risk. Biomed Rep. 2014;2:533-538.

[36] Wiśniewski A, Obojski A, Pawlik A, et al. Polymorphism of the TGFB1 gene is not associated with bronchial allergic asthma in a Polish population. Hum Immunol. 2009;70:134-138.

[37] Mak JC, Leung HC, Ho SP, et al. Analysis of TGF-beta(1) gene polymorphisms in Hong Kong Chinese patients with asthma. J Allergy Clin Immunol. 2006;117: 92-96.

[38] Salam MT, Gauderman WJ, McConnell R, Lin PC, Gilliland FD. Transforming growth factor- 1 C-509T polymorphism, oxidant stress, and early-onset childhood asthma. Am J Respir Crit Care Med. 2007;176:1192-1199.

[39] Dunning AM, Ellis PD, McBride S, et al. A transforming growth factorbeta1 signal peptide variant increases secretion in vitro and is associated with increased incidence of invasive breast cancer. Cancer Res. 2003;63: 2610-2615.

[40] Nakao A, Miike S, Hatano M, et al. Blockade of transforming growth factor beta/Smad signaling in T cells by overexpression of Smad7 enhances antigeninduced airway inflammation and airway reactivity. J Exp Med. 2000;192: $151-158$.

[41] Scherf W, Burdach S, Hansen G. Reduced expression of transforming growth factor beta 1 exacerbates pathology in an experimental asthma model. Eur J Immunol. 2005;35:198-206.

[42] Alvaro M, Sancha J, Larramona H, et al. Allergen-specific immunotherapy: update on immunological mechanisms. Allergol Immunopathol (Madr). 2013; 41:265-272.

[43] Silverman ES, Palmer LJ, Subramaniam V, et al. Transforming growth factorbeta1 promoter polymorphism C-509T is associated with asthma. Am Respir Crit Care Med. 2004;169:214-219.

[44] Acevedo N, Vergara C, Gusmão L, et al. The C-509T promoter polymorphism of the transforming growth factor beta-1 gene is associated with levels of total and specific IgE in a Colombian population. Int Arch Allergy Immunol. 2010; $151: 237-246$

[45] Turner JD, Jackson JA, Faulkner H, et al. Intensity of intestinal infection with multiple worm species is related to regulatory cytokine output and immune hyporesponsiveness. J Infect Dis. 2008;197:1204-1212.

[46] Cooper PJ. Interactions between helminth parasites and allergy. Curr Opin Allergy Clin Immunol. 2009;9:29-37.

[47] Smits HH, Everts B, Hartgers FC, Yazdanbakhsh M. Chronic helminth infections protect against allergic diseases by active regulatory processes. Curr Allergy Asthma Rep. 2010;10:3-12.

[48] Moreau E, Chauvin A. Immunity against helminths: interactions with the host and the intercurrent infections. J Biomed Biotechnol. 2010;2010:428593.

[49] Yamagiwa S, Gray JD, Hashimoto S, Horwitz DA. A role for TGF-beta in the generation and expansion of $\mathrm{CD} 4+\mathrm{CD} 25+$ regulatory $\mathrm{T}$ cells from human peripheral blood. J Immunol. 2001;166:7282-7289.

[50] Rubtsov YP, Rasmussen JP, Chi EY, et al. Regulatory T cell-derived interleukin10 limits inflammation at environmental interfaces. Immunity. 2008;28: 546-558. 


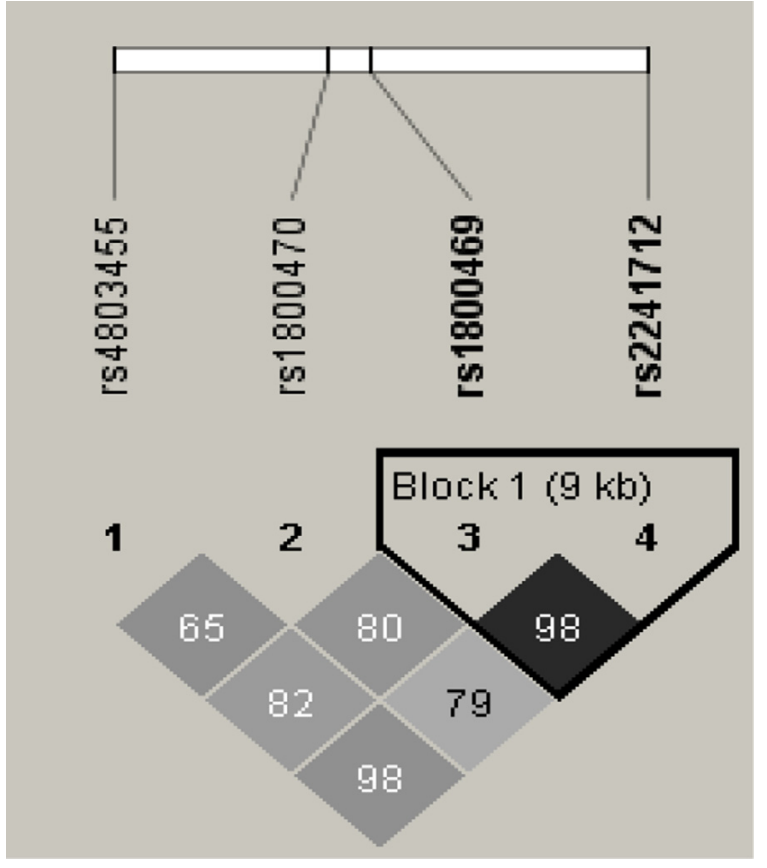

eFigure 1. Pairwise linkage disequilibrium within Haploview by using the $R^{2}$ statistic for the TGFB1 gene. Intensity of shading indicates the degree of confidence in the $R^{2}$ value.
eTable 2

Association Between TGFB1 Haplotypes and Interleukin 10 Production Under Mitogen Stimulation in Total Case-Control Participants by Linear Regression Adjusted for Age, Sex, Helminth Infections, and Principal Components 1 and 2

rs4803455 rs1800470 rs1800469 rs2241712 Frequency $\beta \quad P$ value EMP1

\begin{tabular}{lllllll}
$\mathrm{A}$ & $\mathrm{C}$ & & & 0.08 & $46.8<.001$ & $<.001$ \\
$\mathrm{~A}$ & $\mathrm{C}$ & $\mathrm{C}$ & & 0.06 & $51.1<.001$ & 0.007 \\
$\mathrm{~A}$ & $\mathrm{C}$ & $\mathrm{C}$ & $\mathrm{A}$ & 0.06 & $50.7<.001$ & $9.9 \times 10^{-5}$ \\
\hline
\end{tabular}

Abbreviation: EMP1, empirical $P$ value considering adaptive permutations.

\section{eTable 1}

Association Between Haplotypes of TGFB1 Single-Nucleotide Polymorphisms and Levels of IgG4 Anti-Ascaris lumbricoides in Total Case-Control Participants by Logistic Regression Adjusted for Age, Sex, and Principal Components 1 and 2

\begin{tabular}{llllllll}
\hline rs4803455 & rs1800470 & rs1800469 & rs2241712 & Frequency & $\beta$ & $P$ value & EMP1 \\
\hline & $\mathrm{C}$ & $\mathrm{C}$ & & 0.178 & 1.67 & $9.3 \times 10^{-5}$ & $<.001$ \\
$\mathrm{C}$ & $\mathrm{C}$ & $\mathrm{C}$ & & 0.116 & 1.48 & .01 & .02 \\
& $\mathrm{C}$ & $\mathrm{C}$ & $\mathrm{A}$ & 0.18 & 1.57 & $<.001$ & .001 \\
$\mathrm{C}$ & $\mathrm{C}$ & $\mathrm{C}$ & $\mathrm{A}$ & 0.12 & 1.4 & .03 & .001 \\
\hline
\end{tabular}

Abbreviation: EMP1, empirical $P$ value considering adaptive permutations. 